\title{
A study on Parenting Styles and Parental Attachment in Overcoming Internet Addiction among Children
}

\author{
Nissia Kanan $^{1, *}$, Lawrence Arokiasamy ${ }^{2}$, and Mohd Roslan bin Ismail ${ }^{3}$ \\ International University of Malaya-Wales, Faculty of Business and Law, 50480, Kuala Lumpur, Malaysia
}

\begin{abstract}
Many studies have revealed about Internet use and Internet addiction. Most research focuses on the jeopardy and opportunities about active Internet usage however very limited empirical research emphasis on the role of parents in this context. Hence, this research paper explored the parenting styles and parental attachment in overcoming Internet addiction among children in Klang Valley, Malaysia. The parenting styles model and attachment theory have been used in this research. The Internet has created a new platform for the development of children, which offers various possibilities and also difficulties. Malaysian children are actually very in need to be safe during online thus, parents are encouraged to play their parental role in preparing their children to become better digital citizens.
\end{abstract}

\section{Introduction}

Many studies have proven that internet addiction has given an impact to the children as they were born into a virtual world where they become avid users and spending more time with technology than they do in school or with their family. Internet addiction can be defined as overuse of the Internet leading to impairment of an individual's psychological state (both mental and emotional), as well as their scholastic or occupational and social interactions (Beard \& Wolf, 2001). The number of internet users has been increased from 1999 to 2013 (Internet Live Stats. Internet users), and research on addictive Internet use has been increased as well. DeBell and Champman (2003) from the National Center for Education Statistics found that $23 \%$ of children in nursery school use the Internet, where the most popular uses belonged to children 5-9 years old. Results showed that about $20.5 \%$ spent their time playing games, while $11.7 \%$ of their time was spent on homework. Roberts, L.D., Smith, L.M. \& Pollak, C. (2005) highlighted that 8-10 years olds are the most likely of all age groups to have a video gaming device in the bedroom, spending about 60 minutes a day playing games. Moreover, young children under the age of 3 or 4 years old are more likely to use the internet to watch video clips (Childwise 2012; Findahl 2012; Teuwen, J., De Groff, D., \& Zaman, B., 2012). All these evidences have proven that young children are growing up and reliant on technology in their dayto-day lives.

In Malaysia, there are numerous cases occurred due to internet addictions which is at an alarming rate. Based on studies, International Society of Internet Addiction (ISIA) revealed that 37\% of Malaysian parents worried that their children's online life was contradicting with their home and school obligation while $18 \%$ of children were neglecting basic social activities. As children grow and develop, they need to learn appropriate social behaviours, such as sharing, cooperating, and respecting the property of others in order for them to have have a higher self-esteem and show a greater willingness to interact with their environment. Psychiatrist and Malaysian Mental Health Association deputy president Datuk Dr Andrew Mohanraj also agreed that there is a high risk of internet addiction among shy or socially awkward children while International Society of Internet Addiction spokesman and child psychologist Dr Norharlina Bahar said being online excessively affects the brain and causes biological changes.

Nowadays, there is a worry concerning the internet addiction of children and many studies have discovered this matter as well as important role of parents in overcoming this issue. Parents play a vital role as a coach who engages with children to use technology in creative and interesting ways, apart from games and flashing lights. One of the researches undertaken by Cho and Choi (2005) have found that a positive parent-child attachment can reduces children's exposure to the risky Internet content. Parents' believed that the new technology can be beneficial for their children (e.g seeking information for homework

Corresponding author: lawrence.arokiasamy@iumw.edu.my

(c) The Authors, published by EDP Sciences. This is an open access article distributed under the terms of the Creative Commons Attribution License 4.0 (http://creativecommons.org/licenses/by/4.0/). 
purposes and developing their online skills). Nevertheless, the same technology could also take their children to the danger of the Internet (Guan \& Subrahmanyam, 2009). As a nutshell, this creates awareness within the researcher to discover more in detail about parenting styles and parental attachment in overcoming Internet addiction among children.

\section{Research Problem}

Internet addiction is a very real problem, with real consequences. People who spend hours on the Internet eventually start to see its effects in their lives. The effects of internet addiction gradually minimize the people, activities and pursuits that occupied a person's time before the Internet became an issue. In other words, it can be defined as virtual world orientation which is purpose-built for entertainment, social, educational, training and various other purposes. Today, virtual worlds depict a world very similar to reality, with real-world rules and real-time actions and communications. The most important part here is, it comprises exactly what has captivated children.

Internet addiction has both positive and negative impacts on children. A comprehensive systematic review of epidemiological research of Internet addiction (Kuss DJ, Griffiths MD, Karila L, Billieux J Curr Pharm Des, 2014) reported there are various risk factors associated with Internet addiction, such as sociodemographic variables (male cohort, younger age, and higher family income), Internet use variables (time spent online, using social and gaming applications), psychosocial factors (including impulsivity, neuroticism, and loneliness), and comorbid symptoms (depression, anxiety, and psychopathology in general) are contributing to increase of Internet-use related problems. Rideout, Foehr and Roberts (2010) has announced that children are the most rapidly growing Internet population in the world as well as the most Internet users who spent more time during online.

An addiction refers to the usage of smart phones frequently without being separated from the device. These tendencies are consisted of life disorders which is not able to manage daily life effectively, virtual-world orientation which is being comfortable with the virtual space within the smart phone instead of real life chores and finally withdrawal symptoms such as anxiety and nervousness being away from using the smart phone.

There are many factors that cause Internet addiction. The attractiveness of the Internet could be one of the reasons of frequent use especially for children. Prior research argued that it is not about the Internet addictive, instead its the applications which become addictive, especially highly interactive applications like online chatting, dating, or online gaming (Young, 1998b). In addition, evidence suggested that socialization is also one of the pulling factors behind the power of Internet Addiction (Preece, 2000; Wellman \& Gulia, 1999).

Family performs a crucial position within the personality development of children and adolescents (Ribeiro, 2007; Relvas \& Vaz, 2007). Most parents considered the Internet is beneficial for their children which is helping with homework, and assisting self-realization (Pew Internet \& American Life Projects, 2005). However, many parents are deeply worried about their children's exposure to the Internet and the consequences [35]. Internet addiction among children can be controlled by parents because they are the best mentor to guide and educate their children. Many studies have revealed that quality of parentchild attachment is one of the important factors in identifying the problems that already or may have been occurred among children (Liu Q-X, Fang X-Y, Zhou Z-K, Zhang J-T, Deng L-Y, 2013; Harakeh, Z., Scholte, R. H., Vermulst, A. A., De Vries, H., \& Engels, R. C. M. E., 2004; Van der Vorst, H., Engels, R. C. M. E., Meeus, W., Dekovic, M., \& Van Leeuwe, J., 2005).

Hence, who might be the gatekeepers of children in overcoming Internet addiction? What could be motivating them? The answer is definitely Parents. Attachment theory explained that children will formed attachments in their early formative years with their parents that will shapes their patterns of thought, feeling, and motivation in their future adulthood (Bowlby, 1969). That said, parents could overcome this issue and create a healthy technology usage among children.

\section{Literature Review}

As Internet addiction and electronic entertainment continue to develop and work their way into more children's lives, a rising fear among parents is that children are becoming more susceptible to health-related issues, such as obesity and developmental challenges.

This study is focusing on parenting styles and parental attachment in overcoming Internet addiction among children as parents' words, actions, love and attachment affect their children's developing self-esteem, health and behavior more than anything else. Research reviews are clearly stated that parental involvement and the domestic environment they create are very important for children's early development (AAP, 1999, 2011), and that long-term social inequalities in well being and learning outcomes are shaped by early life experiences, with parental influence being a powerful factor (HM Government, 2014).

Malaysia is an appropriate location for this study because of the extensive use of the nation's aggressive push for Internet connectedness (Malaysian Communications and Multimedia Commission, 2016), parallel to evidence of parental concerns about the impact of the Internet upon children (Soh, P.C.H., Charlton, J., Chew, K.W., 2014). 


\subsection{Parenting Styles}

Parenting styles defines as a set of methodologies or strategies adopted by parents while raising their children [43], and [34] while [24] theory on "parenting styles" concentrated on the effects of home-based parental involvement. However, "A parenting styles is used to capture normal variations in parents' attempts to control and socialize their children" [6]. Originally the theory of Baumrind described on the dimension of control which is parental demandingness, defined as behavioral control refers to "the extent to which parents desire children to become integrated into the family whole, by their maturity demands, supervision, disciplinary efforts and willingness to confront the child who disobeys" [6]. She has discovered three different styles: authoritarian, authoritative, and permissive. Subsequently, the second dimension has been developed by [41], focuses on parental warmth that expanding Baumrind's permissive parenting into two different types: indulgent (permissive) parenting and neglectful (uninvolved) parenting. The combination of parental control and parental warmth known as 'parenting styles'.

On the base of the two dimensions (parental control and parental warmth), there are four broad categories of parenting styles as illustrated in figure 1 .

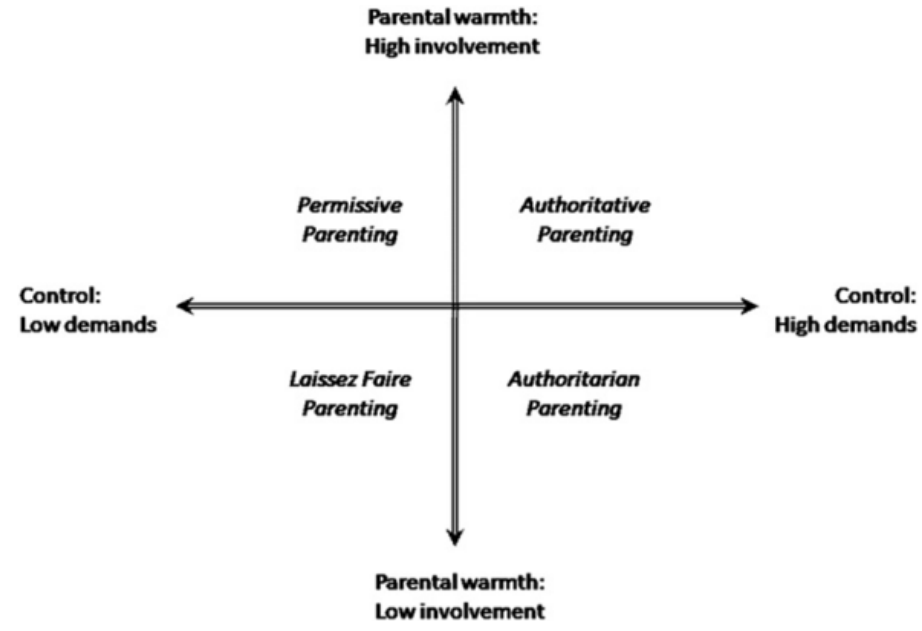

Fig. 1. Parenting styles (based on Baumrind, 1991; Maccoby \& Martin, 1983)

$>$ Authoritative parenting styles is known to be highly responsive yet very demanding, along with nurturing and warm. This type of parenting is thought of as the "best" type of parenting as it's associated with the most successful child outcomes.

$>$ Authoritarian parenting styles is characterized by rigid rules and high demands made by parents. Children are expected to follow the rules, all of the time, with no room for negotiation or exceptions.

$>$ Permissive-indulgent parenting styles known as being indulgent, extremely loving, affectionate and responsive however, they don't expect a lot of their kids and don't offer much in the way of advice or guidelines.

$>$ Permissive-neglectful parenting styles known as parents who do not involve in their kid's lives and typically expect their kids to raise themselves.

Each of these styles have different effects on children based on different background and characteristics of the parents. For instance, authoritative parents are easy to recognize, as they have expectations with an understanding and support. They construct the healthiest environment for a growing child. However, controlling parents create rules and expect their children to follow the rules without explanation (Baumrind, 1971; Chen, X., Dong, Q., \& Zhou, H., 1997; Ishak, Z., Low, S. F., \& Lau, P. L., 2012; Kang \& Moore, 2011; McKinney, Milone, \& Renk, 2011). Besides, permissive parents sets few rules for the children and the rules are inconsistent when they do exist and these children show the least amount of self-confidence. Neglectful parenting is one of the most harmful styles that can be used on a child. They let their children have their way because they do not want to get involved (Jutengren, G., \& Palmerus, K., 2006). Therefore, the present study examines the relationship between parenting styles and Internet addiction among children. 


\subsection{Parental Attachment}

Another variable associated significantly with Internet addiction among children is parental attachment. Parental attachment is correlated with Internet addiction and risky online behavior whereby weak parental-attachment was reported to be a risk factor for children's risky online activities (Lei and Wu, 2007; Yang M. J., (2016) and internet addiction (Soh, et al. 2014). Besides, a significant large body of literature have stated that parents provide a strong foundation towards their children development and have huge influence on their children's behaviour and attitude (Goodman \& Gregg, 2010; Ainsworth, 1989; Armsden \& Greenberg, 1987). Attachment theory explained that children will be attached to the parents in their early formative years that will creates their underlying patterns of thought, feeling, and motivation in their future adulthood (Bowlby, 1969).

Parents in Malaysia has different reactions upon their children's online activities and behaviours, whereby only 4 out of 10 parents know what their children are doing and what they are accessing during online time (Ismail, 2011). Moreover, currently in Malaysia, there is few research conducted on the subject of the risks of internet addiction among children and parental attachment (Soh, C. H., 2010). Therefore, this study is an attempt to fill the gap in the literature that may exist between those lines and explore Internet use, motivations and addiction of children in Malaysia. The researchers also investigate the roles of parents in influencing children online usage, motivations and addiction.

\subsection{Internet Addiction}

Children nowadays are born and raised having technology as an integral part of their daily activities using the internet at home and at school. Goldberg I (1995), a New York-based psychiatrist, first described this condition as an Internet Addiction Disorders. He also defined Internet Addiction as a maladaptive pattern of Internet use leading to clinical impairment or distress, characterized by the presence of typical symptoms. Internet addiction describes the concept that an individual could be too focused and engaged in their online activities that their well-being is neglected (Widyanto and Griffiths, 2006). Besides, the psychological literature generally uses the term 'addiction' to refer to a person's physiological dependence on a stimulus (Davis, 2001).

In Malaysia, more than $90 \%$ of children are using Internet around Klang Valley (Ramayah \& Jantan, 2004) via high speed broadband or smartphone to have an easy access almost anywhere (Zikuhr \& Smith, 2013). What causes them to get addicted to Internet and what are the parental roles to overcome this issue, lead to the questions that have motivated to do this study on the Internet addiction among children in Malaysian. If no precautions are taken, children and young people might face serious dangers and become the victims of internet crimes.

\section{Conceptual Framework}

This conceptual framework indicates the significant relationship between parenting styles, parental attachment and children's Internet addiction. Different parenting styles has different characteristic patterns of thoughts, feelings, and behaviours while parental attachment is also play an important role in children's life.

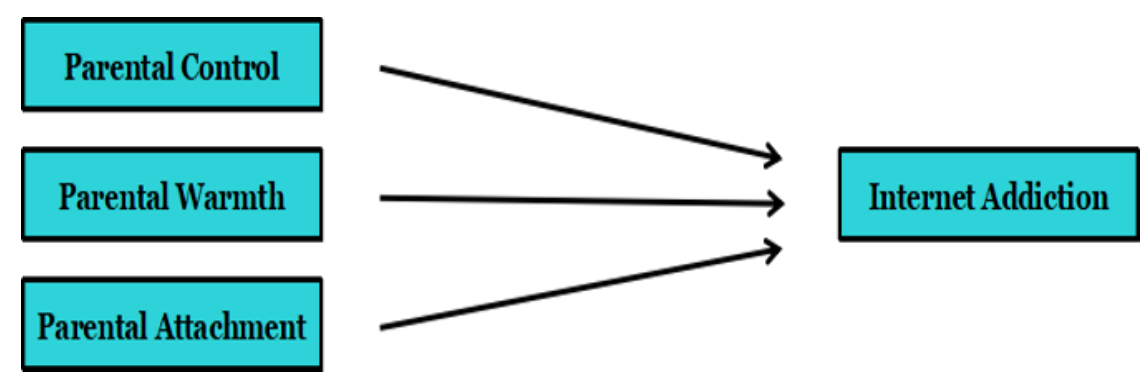

Fig. 2. Conceptual Framework of the Research

\subsection{Parenting Styles and Internet Addiction}

Literature reviews point at a positive impact when parents surf together with their children on the Internet and recommend specific websites (Lee \& Chae, 2007). Most studies refer to types of parental control and parental warmth to identify successful parent interventions (Chou \& Peng, 2007; Heim, J., Brandtzaeg, P., Hertzberg, B., \& Endstad, T., 2007; Kerbs, 2005; Lwin, M. O., Stanaland, A., \& Miyazaki, A., 2008; Valcke, M., Schellens, T., Van Keer, H., \& Gerarts, M., 2007, 
submitted for publication). Valcke, M, et al. 2007 has also found that children that experience explicit parental control report less Internet risk behavior while support of parents leads to safer Internet usage (Fleming et al., 2006). Support and discuss about the Internet seems to result in more educational types of Internet usage and a larger share of positive online interactive behavior (Lee \& Chae, 2007) because children understand to a better extent the complexity of the Internet (Lwin et al., 2008).

However, these are in contrast to the results of some studies which also related to negative findings. For an example, according to (Lee \& Chae, 2007), there is no relationship between restrictive behavior of parents and actual Internet usage of children and this is confirmed by the results of (Heim et al. 2007). A first study about parental control of Eastin, M., Greenberg, B., \& Hofschire, L. (2006) explained that parenting styles did not impact time online which shows less positive impact. In recent times, research has focused on this 'control dimension' of parenting behaviour, arising from research findings that low levels of parental monitoring and high levels of permissiveness are associated with high levels of problem behaviour (Kerr and Stattin, 2003). In addition, (Baumrind, et al. 2011; McKinney, et al. 2011) agreed that controlling parents create an environment with restrictive discipline and punishment (Chan \& Chan, 2005). This harsh and unwarranted punishment will eventually damage the children.

\subsection{Parental Attachment and Internet Addiction}

Children are considered to be attached when they are too close and communicate with a specific caregiver during distress, illness and tiredness (Bowlby, 1969). In the study of Liu and Kuo (2007), it is revealed from a group of Taiwanese students that healthy parent-child relationships and interpersonal relationships correlated negatively with Internet addiction whereas parent-child conflict was founded as positively associated with Internet addiction (Yen, J. Y., Yen, C. F., Chen, C.C., Chen, S. H., \& Ko, C. H., 2007).

Furthermore, Beniot (2004) stated that attachment is different from other aspects of parenting, such as disciplining, entertaining and teaching. Besides, Armsden and Greenberg (in Pearson \& Child, 2007) defined that a strong emotional bond between parents and children can be created by constructing a clear communication in parental attachment. According to a study (Sarina Yusuf, Mohd. Nizam Osman, Md. Salleh Hj. Hassan \& Misha Teimoury, 2014), parent's mutual attachmenttrust towards their children is the main indicator of how they can mitigate the danger and threats that their children may encounter during online.

One of the researches indicated that the quality of a child's attachment creates the child's beliefs regarding the responsiveness and trustworthiness of others (Zeinali, Sharifi, Enayati, Asgari, \& Pasha, 2011) as well as determines the level of security with which that child explores the world, and these early relationships form the models from which future relationships in adolescence and adulthood are developed (Bowlby, 1969; Jenkins-Guarnieri, Wright, \& Hudiburgh, 2012).

\section{Practical Contribution}

Looking at the bigger picture, Malaysia is experiencing both tremendous urbanization processes and challenges. Simultaneously, the process of urbanization brings risks, threats, and challenges. According to the Malaysian Charter (1996), preparing the urban authorities to increase the demands of new era, development and the protection of children is being one of the biggest responsibility. In addition, problems associated with urbanization in Malaysia include the increasing gap in family relations, isolations, and cultural conflicts (Yahaya, 1995). Thus, this study is finding solution on the challenges facing by children nowadays and how could parents play a role influencing on Internet addiction of children.

On the other hand, smartphones, tablets, gaming systems, with so many options it seems almost impossible to limit what (and how much) children views. Thus, industry like Internet Service Provider (ISP) plays a key role in designing the next generation of parental controls, as they significantly shape children's future media experiences. Industry has started to respond to children's online safety matters by adjusting their technical solutions to comply with legal obligations (e.g., regarding content that can or cannot be seen by children), launching parental control features, and/or awareness-raising initiatives. Therefore, the significance of this study is also to address the Industry's responsibility in shaping future importance of parental controls, and making the internet a better place for children.

\section{Conclusion and Implication}

The main objectives of this study is to examine the parenting styles in overcoming Internet addiction among children and to examine the role of parental attachment in overcoming Internet addiction among children. Past studies indicated that the level of Internet usage among children in Malaysia is alarming. 
According to past literature, children that experience clear parental control reports less Internet risk behavior while support of parents leads to safer Internet usage. On the other hand, some studies are also related to negative findings such as punishment will eventually damage the children and associated with high levels of problem behavior.

In addition, attachment between parents and children is also a mutually secure connection, developed over time from birth into the early years of a child's life, and beyond. Thus, it is suggested that the healthy home environment and secure attachments with parents also play a role in the development of internet addiction. Furthermore, this study is important for parents since they reflect the vital role of parent-child relationship in the development of this new disorder-Internet addiction, which if not controlled well in time might become a major problem to encounter with.

By understanding the seriousness of Internet addiction that may affects the children, the concerned parents would probably choose the right parenting styles and implement the appropriate solutions - human-based and technological based. Therefore, the practical strategies of parenting styles in digital culture are highly desirable in raising mobile and web generation.

Finally, regulating Internet content is one of the ways to deter the people especially children from doing wrongful act in the cyber world. One of the key points mentioned in the Malaysian Cyber Law is that there will be no censorship of the Internet (The New Straits Times, 30th April 2007). Therefore, Malaysian Government should take initiative to impose the Internet service provider (ISP) and the telecommunications companies in regulating Internet content and to have optional filtering services for its users.

\section{References}

Armsden, G. C., \& Greenberg, M. T. (1987). The inventory of parent and peer attachment: Individual differences and their relationship to psychological well-being in adolescence. Journal of Youth and Adolescence, 16(5), 427-454.

Ainsworth, M. D. (1989). Attachment beyond infancy. American Psychologist, 44, 709-716.

American Academy of Pediatrics (1999). Media education. Pediatrics, 104, 341-343.

American Academy of Pediatrics, (2011). Council on Communications and Media. Media use by children younger than 2 years. Pediatrics, 128, 1040-1045.

Beard K. W., Wolf E. M. (2001). Modification in the proposed diagnostic criteria for Internet addiction. CyberPsychology \& Behavior, 4(3), 377-383. doi:10.1089/109493101300210286.

Baumrind, D. (1991). The influence of parenting styles on adolescent competence and substance use. Journal of Early Adolescence, 11(1), 56e96.

Bowlby, J. (1969). Attachment and loss: Attachment (1st ed., Vol. I). New York, NY: Basic Books.

Beniot, D., 2004. Infant-parental attachment: definition, types, antecedents, measurement and outcome. Paediatr. Child Health 9 (8), 541-545.

Bowlby, John., 1982. Attachment and loss, vol. 1, Attachment, 2nd ed., Basic Books, New York, NY.

Bleumers, L., Mouws, K., Huyghe, J., van Mechelen, M., Mariën, I., \& Zaman, B. (2015). Sensitivity to parental play beliefs and mediation in young children's hybrid play activities. Proceedings of IDC. Boston, MA: ACM Press, pp. 170177 .

Chan, k., \& Chan, S. (2005). Perceived parenting styles and goal orientations: a study of teacher education students in Hong Kong. Research in Education, 74, 9-21. (EJ751077).

Chou, C., \& Peng, H. (2007). Net-friends: adolescents attitudes and experiences vs. teachers concerns. Computers in Human Behavior, 23, 2394e2413.

Cho, C. H., \& Choi, H. J. (2005). Children's exposure to negative Internet content: Effects of family context. Journal of Broadcasting \& Electronic Media, 49(4), 488-509.

Childwise. (2012). The monitor pre-school report 2012: key behavior patterns among 0 to 4 year olds, Norwich. 
Chen, X., Dong, Q., \& Zhou, H. (1997). Authoritative and authoritarian parenting practices and social and school performance in Chinese children. International Journal of Behavioral Development, 21, 855-873.

Davis, R. A. (2001). A cognitive- behavioral model of pathological Internet use. Computers in Human Behavior, 17, 187195.

DeBell, M., and Chapman, C. (2003). Computer and Internet use by Children and Adolescents in the United States, 2001 (NCES 2004-014). Washington, DC: U.S. Department of Education, National Center for Education Statistics.

Donoso, V., Verdoodt, V., van Mechelen, M., \& Jasmontaite, L. (2016). Faraway, so close: Why the digital industry needs scholars and the other way around. Journal of Children and Media (in press).

Eastin, M., Greenberg, B., \& Hofschire, L. (2006). Parenting the Internet. Journal of Communication, 56, $486 \mathrm{e} 504$.

Fleming, J., Greentree, S., Cocotti-Muller, D., Elias, K., \& Morrison, S. (2006). Safety in Cyberspace. Youth and Society, $38(2), 135 \mathrm{e} 154$.

Findahl, O. (2012). Swedes and the Internet 2012.

Goodman, A. \& Gregg, P. (2010). Poorer children's educational attainment: How important are attitudes and behaviour?. Joseph Rowntree Foundation Report. Retrieved from http://www.jrf.org.uk/

Guan S. A. \& Subrahmanyam (2009) Youth Internet Use: Risks and Opportunities. Curr Opin Psychiatry. 22(4): 351-356.

Grolnick, W. S., \& Ryan, R. M. (1989). Parent styles associated with children's self-regnlation and competence in school. Journal of Educational Psychology, 81, 143-154.

Heim, J., Brandtzaeg, P., Hertzberg, B., \& Endstad, T. (2007). Children's usage of media technologies and psychosocial factors. New Media \& Society, 9(3), 425e454

Harakeh, Z., Scholte, R. H., Vermulst, A. A., De Vries, H., \& Engels, R. C. M. E. (2004). Parental factors and adolescents' smoking behavior: an extension of the theory of planned behavior. Preventive Medicine, 39(5), 951-961.

HM Government (2014) An Evidence Review of the Drivers of Child Poverty for Families in Poverty Now and for Poor Children Growing up to be Poor Adults. Cm8781.

Ishak, Z., Low, S. F., \& Lau, P. L. (2012). Parenting style as a moderator for students' academic achievement. Journal of Science Education \& Technology, 21, 487-493.

Jenkins-Guarnieri, M. A., Wright, S. L., \& Hudiburgh, L. (2012). The relationships among attachment style, personality traits, interpersonal competency, and Facebook use. Journal of Applied Developmental Psychology, 33, 294-301.

Kang, Y. \& Moore, J. (2011). 'Parenting style and adolescents' school performance inmainland China'. US- China Education Review, B (1), 133-138.

Kerr, M. and Stattin, H. (2003) 'Parenting of adolescents: Action or Reaction?' In: A.C. Crouter and A. Booth (eds.), Children's Influence on Family Dynamics: The Neglected Side of Family Relationships. Mahwah, NJ: Lawrence Erlbaum Associates, pp. 121-52.

Kerbs, R. (2005). Social and ethical considerations in virtual worlds. Retrieved on November 8, 2008.

Kuss, D. J., Griffiths, M. D., Karila, L., \& Billieux, J. (2014). Internet addiction: A systematic review of epidemiological research for the last decade. Current Pharmaceutical Design, 20, 4026-4052.

Kalil, A., Ryan, R., \& Corey, M. (2012). Diverging Destinies: Maternal Education and the Developmental Gradient in Time with Children. Demography, 49(4), 1361-1383. 
Livingstone, S., \& Bober, M. (2004). UK children go online: Surveying the experiences of young people and their parents. Retrieved on March 19, 2009 from. http:// www.york.ac.uk/res/e-society/projects/1/UKCGOsurveyreport.pdf.

Lwin, M. O., Stanaland, A., \& Miyazaki, A. (2008). Protecting children's privacy online: how parental mediation strategies affect website safeguard effectiveness. Journal of Retailing, 84, 205e217

Lee, S., \& Chae, M. A. (2007). Children's Internet use in a family context: influence on family relationships and parental mediation. Cyberpsychology \& Behavior, 10(5), 640e644.

Lei, L., \& Wu, Y. (2007). Adolescents' paternal attachment and Internet use. Cyber Psychology \& Behavior, 10(5)

Liu Q-X, Fang X-Y, Zhou Z-K, Zhang J-T, Deng L-Y (2013) Perceived Parent-Adolescent Relationship, Perceived Parental Online Behaviors and Pathological Internet Use among Adolescents: Gender-Specific Differences. PLoS ONE 8(9): e75642. doi:10.1371/journal.pone.0075642.

Liu, C. Y., \& Kuo, F.Y.(2007). A study of Internet addiction through the lens of the interpersonal theory. CyberPsychology \& Behavior, 10(6), 799-804.

Maccoby, E.E. and Martin, J.A. (1983) 'Socialization in the context of the family: Parent-child interaction'. In: P.H. Mussen (Series Ed.) and E.M. Hetherington (Volume Ed.), Handbook of Child Psychology. Volume 4: Socialization, personality and social development (4th edition). New York: Wiley, pp. 1-101.

Malaysian Communications and Multimedia Commission (2016). Internet Users Survey 2016.

McGencey, S. (2011). The time is now: creating opportunities for young children to succeed. National Civic Review 100(4), 56-58.

McKinney, C., Milone, M. C., \& Renk, K. (2011). Parenting and late adolescent emotional adjustment: Mediating effects of discipline and gender. Child Psychiatry and Human Development, 42, 463-481. doi: 10.1007/s10578- 0110229-2.

Nouwen, M., Van Mechelen, M. and Zaman, B., 2015. A value sensitive design approach to parental software for young children, Proc. IDC 2015. 363-366.

Pew Internet \& American Life Project (PI \& ALP). (2005b). Teens and technology. Washington D. C,: Pew Internet \& American Life Project.

Preece, J. (2000). Online communities: Designing usability, supporting sociability. Chichester, England: John Wiley \& Sons.

Pearson, J. C. \& Child, J. T. (2007). A Cross-Cultural Comparison of Parental and Peer Attachment Styles among Adult Children from the United States, Puerto Rico, and India. Journal of Intercultural Communication Research. 36(1): 15-32.

Rideout, V.J., Foehr, U.G., \& Roberts, D.F. (2010). Generation M2: Media in the lives of 8- to 18-year olds. (Kaiser Report 2010). Retrieved from http://www.kff.org/entmedia/upload/8010.pdf

Ramayah, T., \& Jantan, M. (2004). Internet usage among Malaysian students: The role of demographic and motivational variables. The Journal of Management Awareness, 7(2), 5970.

Roberts, L.D., Smith, L.M. \&Pollak, C.(2005). A model of social interaction via computer mediated communication in real text- based virtual environments,psychcentral.com/Netaddiction/.

Ribeiro, M. (2007). Children and divorce. Lisbon: Editorial Presence.

Relvas, A., \& Vaz, C. (2007). Single parenthood: A family a part or part of the family. In A. Relvas, \& M. Alarcão (Eds.), New forms of family (pp. 253-269). Coimbra: Quartet. 
Sarina Yusuf, Mohd. Nizam Osmana, Md. Salleh Hj. Hassana \& Misha Teimoury Misha (2014) Parents' influence on children's online usage. Procedia - Social and Behavioral Sciences, 155. pp. 81-86. ISSN 1877-0428.

Soh, C. H. (2010) Influence of Parents and Peers On Internet Usage and Addiction Amongst School-Going Youths in Malaysia. Malaysian University of Science and Technology, Malaysia.

Soh, P.C.H., Charlton, J., Chew, K.W., 2014. The influence of parental and peer attachment on internet usage motives and addiction. First Monday 19 (7).

Teuwen, J., De Groff, D., \& Zaman, B. (2012). Flemish preschoolers online: a mixed-method approach to explore online use, preferences and the role of parents and siblings. Paper presented at the Etmaal van de Communicatiewetenschap, Leuven, Belgium.

Valcke, M., Schellens, T., Van Keer, H., \& Gerarts, M. (2007). Primary school children's safe and unsafe use of Internet at home and at school: an exploratory study. Computers in Human Behavior, 23, 2838e2850

Valcke, M., Schellens, T., Van Keer, H., \& Gerarts, M. Primary school children's safe and unsafe use of Internet at home and at school: a follow-up study, submitted for publication.

Valcke M, Bonte S, De Wever B, Rots I. Internet parenting styles and the impact on Internet use of primary school children. Comput Educ 2010; 55: 454-64.

Van der Vorst, H., Engels, R. C. M. E., Meeus, W., Dekovic, M., \& Van Leeuwe, J. (2005). The role of alcohol-specific socialization in adolescents' drinking behaviour. Addiction, 100(10), 1464- 1476

Widyanto, L., Griffiths, M., 2006. Internet addiction; does it really exist? (revisited). In: Gackenbach, J. (Ed.), Psychology and the Internet: Intrapersonal, Interpersonal, and Transpersonal Implications, 2nd ed. Academic Press, New York.

Wellman, B., \& Gulia, M. (1999). Virtual communities as communities. In M. A. Smith \& P. Kollock (Eds.), Communities in cyberspace (pp. 167-194). London: Routledge.

Yahaya Ibrahim (1995). Urbanization and Neighborhood. Dewan Bahasa \& Pustaka: Kuala Lumpur.

Young, K. S. (1998). Internet addiction; the emergence of new clinical disorder. CyberPsychology \& Behavior, 1, $237-244$.

Yen, J. Y., Yen, C. F., Chen, C.C., Chen, S. H., \& Ko, C. H. (2007). Family factors of Internet addiction and substance use experience in Taiwanese adolescents. CyberPsychology \& Behavior, 10, 323-329.

Zickhur, K. \& Smith, A. (2013). "Home Broadband 2013” http://www.pewinternet.org/2013/08/26/home-broadband2013/Pew Internet \& American Life Project. Washington D. C.

Zeinali A, Sharifi H, Enayati M, Asgari P, Pasha GH, 2011. Development and validation of parenting styles questionnaire. Journal of New Thoughts of Educational Sciences. 6(3): 129-145.

Ismail, Ikram. (2011, October 12). Cyber- duped parents, The Malay Mail, p.7. 1

Goldberg I (1995). Internet Addictive Disorder (IAD) diagnostic criteria.

Baumrind, D. (1971). Current patterns of parental authority. Developmental Psychology Monograph, 4,1-103.

Greening, L., Stoppelbein, L., \& Luebbe, A. (2010). The moderating effects of parenting styles on African American and Caucasian children's suicidal behaviors. Journal of Youth \& Adolescence, 39, 357-369. doi: 10.1007/s10964009-9459-z.

Trinkner, R., Cohn, E. S., Rebellon, C. J., \& Van Gundy, K. (2012). Don't trust anyone over 30: Parental legitimacy as a mediator between parenting style and changes in delinquent behavior over time. Journal of Adolescence, 35, $119-132$. doi: 10.1016 /j.adolescence.2011.05.003. 
Jutengren, G., \& Palmerus, K. (2006). The potential role of conflict resolution schemas in adolescent psychosocial adjustment. Social Indicators Research, 83,25-38.doi:10.1007/s11205-006- 9066-2 